\title{
STRATEGI PENGELOLAAN HUTAN RAKYAT PINANG JAYA KEMILING DENGAN ANALISIS SWOT
}

\author{
(Pinang Jaya Kemiling Community Forest Management Strategy With SWOT Analysis)
}

\section{Siti Herawati Sitorus, Rahmat Safe'i, Susni Herwanti}

Jurusan Kehutanan, Universitas Lampung

J1. Prof. Sumantri Brojonegoro No.1 Bandar Lampung 35145

rahmat.safei@fp.unila.ac.id

\begin{abstract}
Community forest has a very important role in influencing environmental sustainability. Good management at community forest will affect the welfare of the community around the forest. This study aims to determine the strategy of community forest management in Pinang Jaya Kemiling Bandar Lampung. The data were collected with observation, documentation study and deeply interview with community forest farmers. The method of analysis used in this research is descriptive qualitative. The strategy for managing the community forest in Pinang Jaya analyzed with SWOT analysis (Strengths, Weaknesses, Opportunities and Threat). Based on the research, the results of the identification of internal factors, there are two strengths and four weaknesses, Meanwhile for external factors, there are five opportunities and one threat. The SWOT diagram shows that the position of the Pinang Jaya comunnity forest management strategy lies in quadrant three or diversification strategy by use the power possessed and avoid any available threats.
\end{abstract}

Keywords : Community forest, management at community forest, SWOT

\section{Abstrak}

Hutan rakyat memiliki peran yang sangat penting dalam mempengaruhi kelestarian lingkungan. Pengelolaan hutan rakyat yang baik akan berdampak pada kesejahteraan masyarakat sekitar hutan. Penelitian ini bertujuan untuk mengetahui strategi pengelolaan hutan rakyat di Pinang Jaya Kemiling Bandar Lampung. Pengumpulan data dilakukan dengan observasi, studi dokumentasi dan wawancara mendalam dengan petani hutan rakyat. Metode analisis yang digunakan dalam penelitian ini adalah deskriptif kualitatif. Strategi pengelolaan hutan rakyat di Pinang Jaya dianalisis dengan analisis SWOT (Strengths, Weaknesses, Opportunities and Threat). Berdasarkan penelitian diperoleh hasil identifikasi faktor internal terdapat dua kekuatan dan empat kelemahan, sedangkan untuk faktor eksternal terdapat lima peluang dan satu ancaman. Diagram SWOT menunjukkan bahwa posisi strategi pengelolaan hutan rakyat Pinang Jaya berada pada kuadran tiga atau strategi diversifikasi dengan menggunakan kekuatan yang dimiliki dan menghindari ancaman yang ada.

Kata Kunci: Hutan rakyat, Pengelolaan Hutan rakyat, SWOT

\section{PENDAHULUAN}

Hutan rakyat merupakan hutan yang dikelola oleh rakyat di atas tanah miliknya sendiri. Manfaat hutan rakyat dapat dirasakan jika dikelola dengan baik. Manfaat yang diperoleh masyarakat tergantung pada pengelolaan yang dilakukan oleh petani hutan rakyat (Butar $e t$ al. 2019). Hutan rakyat dapat memberikan dampak positif salah satunya ialah hasil hutan dapat dimanfaatkan oleh masyarakat. Hal ini sejalan dengan penelitian Safe'i et al. (2017) bahwa komoditas tanaman kehutanan (pepohonan/kayu) dan tanaman pertanian (semusim/non kayu) merupakan hasil hutan yang dapat dimanfaatkan di hutan rakyat. 
Hutan rakyat berkontribusi dalam memperbaiki lingkungan yang semula tandus dan kritis kini menjadi kawasan yang hijau dan subur. Hutan rakyat yang dibangun di lahan-lahan kritis berperan dalam melindungi bahaya erosi, sedangkan hutan rakyat yang memiliki jenis-jenis tertentu dapat meningkatkan kesuburan tanah. Salah satu faktor agar hutan tetap terjaga keseimbangan ekologi ialah keanekaragaman jenis tanaman yang tinggi (Safe'i et al. 2018). Manfaat dari keanekaragaman jenis tanaman yang tinggi ialah sebagai penyeimbang ekosistem.

Keberadaan hutan rakyat di tengahtengah masyarakat memberikan manfaat yang sangat luas dengan demikian hutan rakyat harus dijaga kelestariannya. Tujuan dari pengelolaan hutan berkelanjutan ialah memberikan keuntungan ekonomi dari pemilik hutan, untuk meningkatkan kesejahteraan masyarakat, demokrasi pedesaan, dan ketertiban sosial (misi sosial) (Yiwen et al. 2019). Pengelolaan hutan rakyat yang baik akan berdampak pada kesejahteraan masyarakat sekitar hutan rakyat.

Hutan rakyat di Kelurahan Pinang Jaya merupakan salah satu kelurahan yang ada di Kecamatan Kemiling yang memiliki luas sebesar 195 Ha. Pengelolaan Hutan Rakyat di Pinang Jaya sebagian besar menerapkan sistem agroforestri. Petani hutan rakyat menerapkan sistem agroforestri karena membantu penggunaan lahan secara optimal sehingga dapat memperbaiki kebutuhan hidup masyarakat. Peran masyarakat dalam pengelolaan hutan rakyat menjadi sangat penting karena menjadi salah satu sumber mata pencaharian masyarakat. Keberadaan masyarakat dalam mengelola hutan rakyat memiliki pengaruh yang besar dalam pelestarian hutan. Ada beberapa kendala yang terjadi di Hutan Rakyat Pinang Jaya yaitu sudah terjadinya alih fungsi lahan, kurangnya perencanaan pengelolaan yang tidak terstruktur, belum terjaminnya kualitas dan hasil produksi hasil hutan, tidak adanya kegiatan kelompok tani yang rutin dilaksanakan dan kurangnya pengetahuan petani terkait pengelolaan.

Kelemahan terbesar yang terjadi di hutan rakyat Pinang Jaya ialah terjadinya alih fungsi lahan karena lokasi hutan rakyat yang berada di wilayah perkotaan. Kelurahan Pinang Jaya sendiri merupakan wilayah perkotaan yang menjadi salah satu daerah untuk dijadikan pengembangan perumahan di wilayah sekitar perkotaan. Agar dapat mengoptimalkan pengelolaan hutan rakyat di Kelurahan Pinang Jaya diperlukan strategi yang dibangun dengan memperhatikan kondisi pengelolaan yang ada saat ini. Strategi ini dirumuskan berdasarkan faktor internal dan faktor eksternal yang merupakan kekuatan, kelemahan, peluang dan ancaman atas pengelolaan hutan rakyat yang ada di Kelurahan Pinang Jaya melalui analisis SWOT. Oleh karena itu, penelitian ini penting untuk merumuskan bagaimana strategi pengelolaan hutan rakyat tersebut.

\section{METODE PENELITIAN}

Penelitian ini dilaksanakan di hutan rakyat Pinang Jaya Kecamatan Kemiling, Kota Bandar Lampung. Penelitian ini dilaksanakan selama dua bulan yaitu Februari-Maret 2020. Alat yang akan digunakan meliputi alat tulis, daftar pertanyaan (kuesioner), kamera, kalkulator, laptop dan alat perekam. Sedangkan objek 
penelitian ini adalah anggota kelompok tani hutan rakyat Pinang Jaya, yang mengelola lahan hutan rakyat dan data pendukung dari instansi dan literatur yang terkait.

Data yang digunakan dalam penelitian ini adalah data primer dan sekunder. Data primer merupakan data yang diperoleh langsung dari responden melalui wawancara secara langsung dengan menggunakan daftar pertanyaan (kuesioner yang telah disusun). Data sekunder diperoleh melalui studi pustaka/literatur yaitu dengan cara membaca dan mengutip teori-teori yang relevan dari berbagai sumber, serta data-data yang didapat dari lembaga-lembaga/instansi-instansi yang terkait dengan penelitian ini. Data yang diambil ialah data yang mendukung penelitian ini seperti gambaran umum lokasi penelitian, data statistik identitas penduduk, kebijakan pemerintah yang mendukung usahatani hutan rakyat, bentuk pengelolaan hutan rakyat dan bentuk pengembangan hutan rakyat.

Pengambilan responden dilaksanakan dengan menggunakan teiknik (random sampling). Jumlah anggota kelompok tani di Kelurahan Pinang Jaya sebanyak 100 orang. Berdasarkan populasi tersebut, jumlah sampel yang akan diambil pada anggota kelompok tani Kelurahan Pinang Jaya sebesar 50 responden. Batas error yang digunakan pada penelitian ini adalah $10 \%$ karena jumlah responden tersebut sudah mewakili informasi yang dibutuhkan. . Berdasarkan formula Slovin (Arikunto, 2011), maka didapatkan jumlah responden pada penelitian ini yaitu.

$$
\mathrm{n}=\frac{\mathrm{N}}{1+\mathrm{Ne}^{2}}
$$

$\mathrm{n}=\frac{100}{1+100(0,10)^{2}}=50$ responden

Keterangan :

$\mathrm{n}=$ Jumlah sampel responden yang diambil dalam penelitian

$\mathrm{N}=$ Jumlah populasi petani anggota kelompok yang ada di lokasi penelitian

$\mathrm{e}=$ Presisi/batas eror (10\%)

1 = Bilangan konstanta

Pengolahan data dalam metode SWOT memerlukan responden khusus dalam penentuan bobot dan peringkat, karena penentuan bobot dan peringkat tidak dilakukan oleh peneliti. Reponden tersebut terdiri dari pengurus kelompok tani hutan rakyat, penyuluh kehutanan Kota Bandar Lampung, dosen jurusan kehutanan, Fakultas Pertanian, Universitas Lampung, pihak dinas kehutanan Provinsi Lampung, dan pihak BPDASHL Way Seputih-Way Sekampung. Kriteria penentuan reponden dipilih secara khusus dengan ketentuan memahami perkembangan dan pengelolaan hutan rakyat. Responden penentuan bobot dan peringkat ini dipilih secara purposive sampling. Dalam merumuskan strategi pengelolaan hutan rakyat Kelurahan Pinang Jaya dilakukan analisis data dengan menggunakan analisis SWOT dengan mengidentifikasi berbagai faktor secara sistematis dengan cara merumuskan empat kuadran dalam analisis SWOT (strategi SO, ST, WO, dan WT). Analisis ini didasarkan pada keputusan yang dapat memaksimalkan kekuatan (strength) dan peluang (opportunities) namun secara bersamaan dapat meminimalisirkan kelemahan (Weakness) dan Ancaman (Threat). Analisis SWOT dilakukan dengan mengidentifikasi berbagai faktor secara sistematis untuk merumuskan strategi (Rangkuti, 2004). 


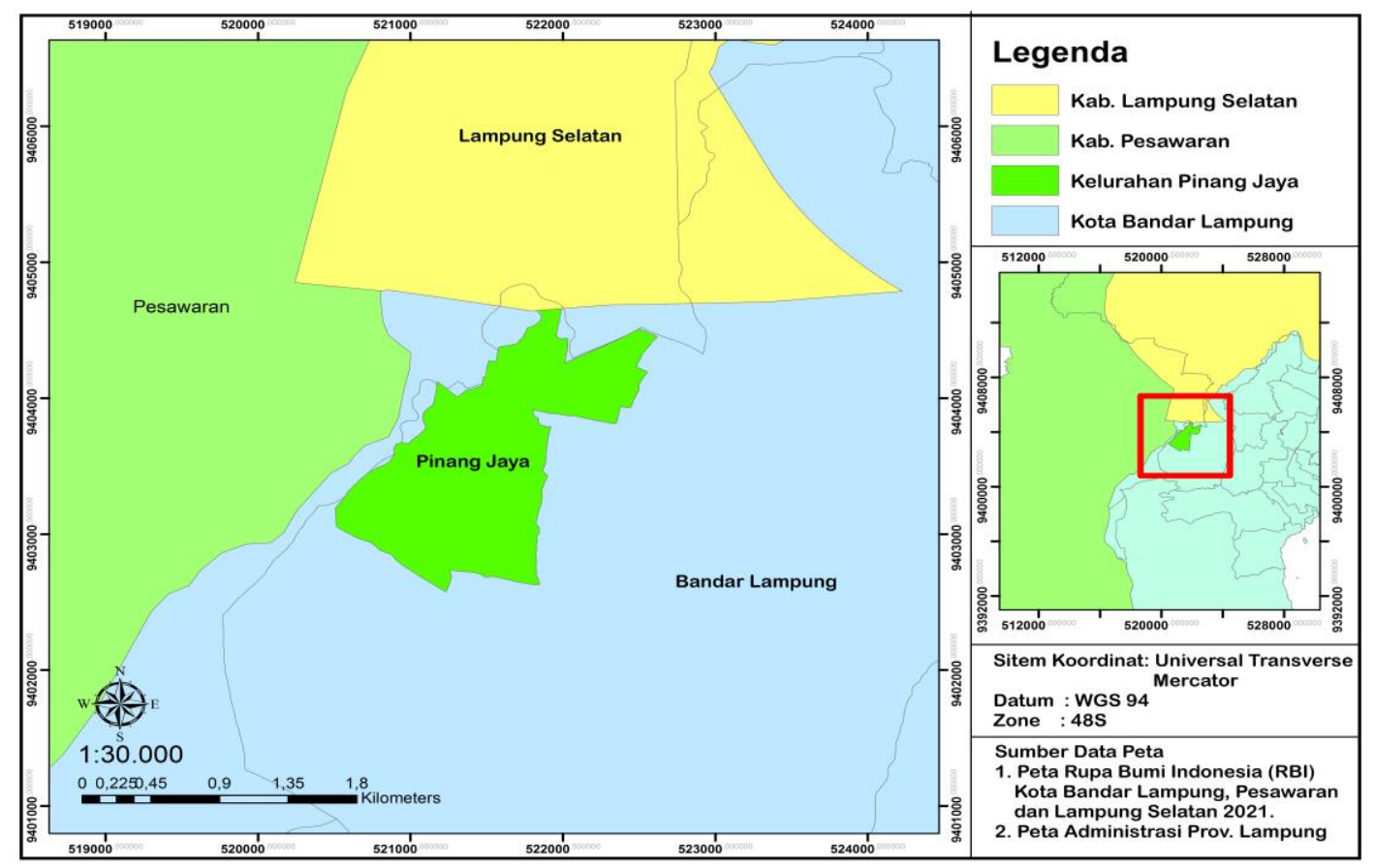

Gambar 1. Lokasi penelitian hutan rakyat Pinang Jaya, Kecamatan Kemiling

\section{HASIL DAN PEMBAHASAN}

\section{A. Faktor Internal}

Faktor-faktor internal pada pengelolaan hutan rakyat Pinang Jaya terdiri dari faktor kekuatan dan kelemahan. Hasil yang didapatkan berdasarkan analisis IFE, diperoleh 2 (dua) faktor kekuatan internal (strenght) dan 4 (empat) faktor kelemahan (weaknes). Perhitungan total skor bobot pada matriks IFE disajikan pada Tabel 1.

\section{Tabel 1. Matriks IFE (Internal Factor Evaluation Matrix)}

\begin{tabular}{llll}
\hline Faktor Kunci Internal & Bobot & Peringkat & Skor \\
\hline Kekuatan & & & \\
1. Tersedianya tenaga kerja keluarga & 0,43 & 3 & 1,29 \\
2. Status penguasaan lahan & 0,57 & 4 & 2,28 \\
\hline Sub Total & $\sum=1$ & & 3,57 \\
\hline Kelemahan & & & \\
1. Organisasi petani yang lemah & 0,22 & 2 & 0,44 \\
2. Partisipasi petani yang rendah terhadap kegiatan & 0,26 & 2 & 0,52 \\
$\quad$ penyuluhan & & & \\
3.Pendapatan petani yang rendah & 0,25 & 1 & 0,25 \\
4. Alih fungsi lahan & 0,27 & 2 & 0,54 \\
\hline Sub Total & $\sum=1$ & & 1,75 \\
\hline
\end{tabular}

Berdasarkan hasil analisis Internal Factor Evaluation (IFE) pada Tabel 1, faktor-faktor kekuatan internal yang memengaruhi pengelolaan hutan rakyat terdiri dari tersedianya tenaga kerja keluarga dan status penguasaan lahan. Status penguasaan lahan memiliki skor tertinggi pada faktor kekuatan yaitu $(2,28)$. Skor tersebut menunjukkan bahwa status penguasaan lahan memiliki 
dampak yang penting untuk pengelolaan hutan rakyat. Berdasarkan hasil wawancara yang telah dilakukan, dari 50 responden petani, 47 responden petani memiliki hak pengusaan lahan hutan rakyat. Hal tersebut dapat memberikan dampak yang baik untuk pengelolaan hutan rakyat Pinang Jaya sedangkan 3 reponden menggarap lahan milik orang lain dengan bagi hasil. Adapun faktorfaktor kelemahan internal yang melingkupi pengelolaaan hutan rakyat adalah organisasi petani yang lemah, partisipasi petani yang rendah terhadap kegiatan penyuluhan, pendapatan petani yang rendah, dan alih fungsi lahan. Alih fungsi lahan pada faktor kelemahan memiliki skor $(0,54)$. Skor tersebut merupakan skor tertinggi pada faktor kelemahan. Hal ini menunjukkan bahwa alih fungsi lahan memiliki dampak yang sangat buruk pada pengelolaan hutan rakyat. Berdasarkan hasil wawancara yang telah dilakukan sebagian besar masyarakat Pinang Jaya menjual lahannya kepada pengembang perumahan (developer) karena kebutuhan yang mendesak, sehingga terjadilah alih fungsi lahan.

Berdasarkan hasil perhitungan skor bobot total pada faktor kekuatan internal dengan menggunakan matriks IFE diperoleh skor berbobot 3,57. Secara umum kondisi pengelolaan hutan rakyat Pinang Jaya berada dalam posisi kuat secara internal. Hal ini dikarenakan total skor bobot pada faktor kekuatan internal lebih dari 2,50. Hal ini sejalan dengan penelitian Supriono. et al (2013) bahwa skor bobot dalam analisis matriks EFE lebih dari 2,50 berada dalam posisi kuat secara internal. Perhitungan total skor bobot pada matriks EFE disajikan pada Tabel 1.

\section{B. Faktor eksternal}

Sementara analisis faktor-faktor eksternal pada pengelolaan hutan rakyat terdiri dari faktor peluang dan faktor ancaman. Berdasarkan analisis matrisks EFE terdapat 5 (lima) faktor peluang (opportunities) dan 1 (satu) faktor ancaman (threat). Perhitungan total skor bobot pada matriks EFE disajikan pada Tabel 2.

\section{Tabel 2. Matriks EFE (Eksternal Factor Evaluation Matrix)}

\begin{tabular}{llll}
\hline Faktor Kunci Eksternal & Bobot & Peringkat & Skor \\
\hline Peluang & & & \\
1. Adanya pasar & 0,20 & 3 & 0,60 \\
2. Adanya kebijakan pemerintah & 0,22 & 3 & 0,66 \\
3. Adanya bantuan bibit dan pupuk dari pemerintah & 0,16 & 3 & 0,48 \\
4. Lokasi geografis yang strategis & 0,24 & 4 & 0,96 \\
5. Aksesibilitas yang mudah & 0,18 & 3 & 0,54 \\
\hline Sub Total & $\sum=1$ & & 3,24 \\
\hline Ancaman & & & 2,00 \\
1. Adanya hama dan penyakit pada tanaman & 1 & 2 & 2,00 \\
\hline Sub Total & $\sum=1$ & & \\
\hline
\end{tabular}

Berdasarkan hasil matriks EFE (External Factor Evaluation) pada Tabel 2, peluang yang dimiliki oleh hutan rakyat Pinang Jaya sebanyak 5 (lima) faktor, yaitu adanya pasar, adanya kebijakan pemerintah, adanya bantuan 
bibit dan pupuk dari pemerintah, lokasi geografis yang strategis, dan aksesibilitas yang mudah. Lokasi geografis yang strategis memiliki skor tertinggi pada faktor peluang yaitu $(0,96)$. Hal tersebut menunjukkan bahwa geografis yang strategis memiliki pengaruh yang besar untuk pengelolaan hutan rakyat. adanya hama dan penyakit pada tanaman merupakan faktor ancaman yang terjadi di hutan rakyat Pinang Jaya. Adanya hama dan penyakit pada tanaman memiliki skor sebesar $(2,00)$ hal tesebut menunjukkan bahwa hama dan penyakit dapat memberikan pengaruh yang buruk. Imbasnya pendapatan petani menurun karena hasil dari hutan rakyat yang tidak optimal.

Perhitungan total nilai yang dibobot pada matriks EFE, dapat diketahui bahwa secara umum kondisi hutan rakyat dalam situasi dapat memanfaatkan peluang yang ada sekaligus meminimalisirkan pengaruh negatif dari ancaman eksternal. Hal ini ditunjukan oleh nilai skor total pada faktor peluang sebesar 3,24 atau lebih dari 2,50.

Tabel 3. Pembobotan untuk diagram SWOT faktor internal dan eksternal

\begin{tabular}{lcccc}
\hline Uraian & \multicolumn{2}{c}{ Faktor Internal } & \multicolumn{2}{c}{ Faktor eksternal } \\
\hline \multirow{2}{*}{ Bobot x Peringkat } & Kekuatan & Kelemahan & Ancaman & Peluang \\
Selisih & 3,57 & 1,75 & 2,00 & 3,24 \\
\hline
\end{tabular}

Berdasarkan hasil pembobotan untuk diagram SWOT faktor internal dan eksternal, maka dihasilkan selisih dari faktor internal yaitu $+1,82$ sedangkan selisih dari faktor eksternal yaitu $-1,24$.
Setelah diperoleh angka dari selisih dari faktor internal dan eksternal, maka dapat dibuat diagram SWOT, dapat dilihat pada Gambar 1. 


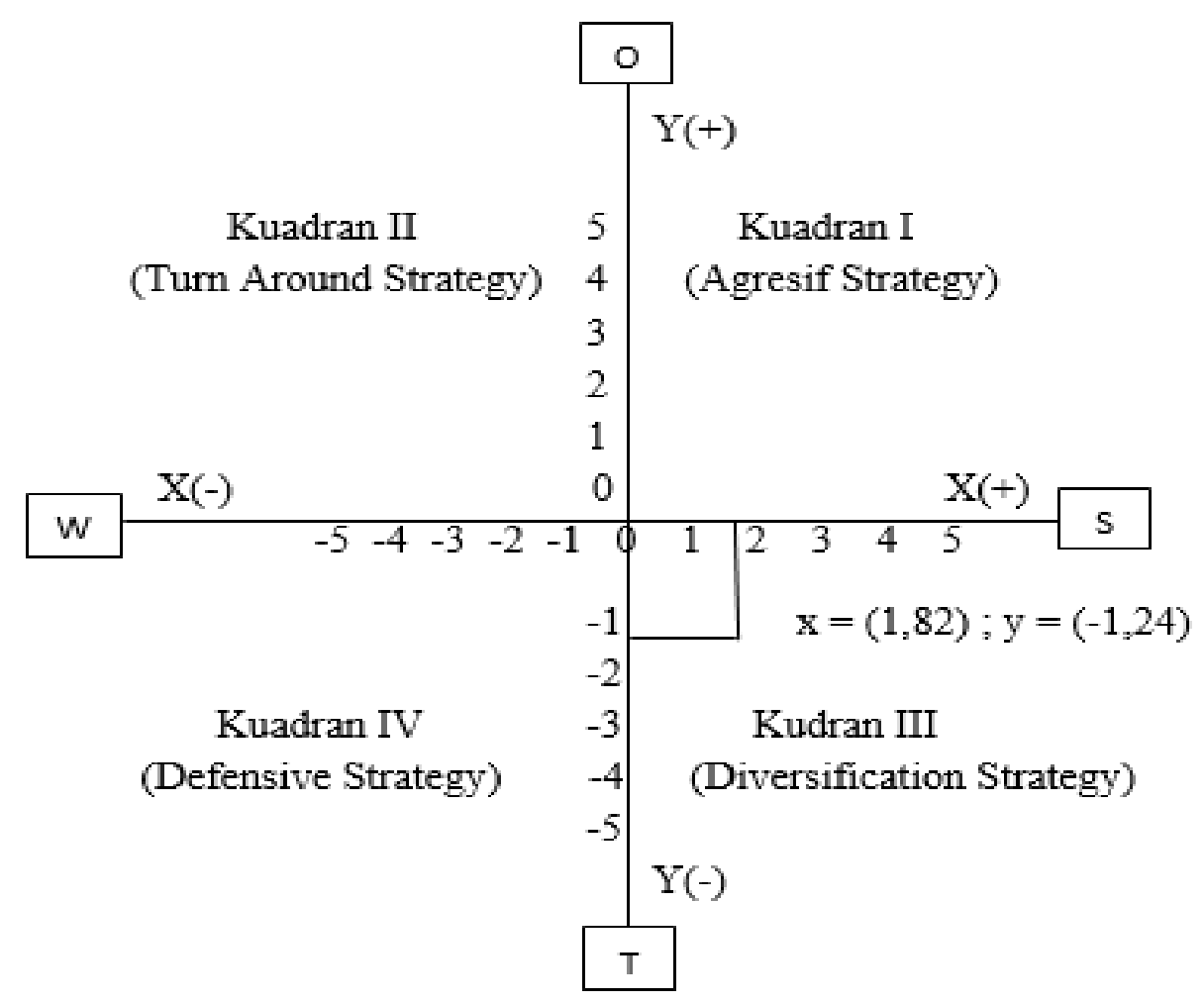

Gambar 2. Matriks SWOT Strategi Pengelolaan Hutan Rakyat Pinang Jaya

Pada Gambar 1 menunjukkan nilai $\mathrm{x}>0$ yaitu 1,82 dan nilai $\mathrm{y}<0$ yaitu $(-1,24)$. Jika dilihat pada nilai $x$ dan nilai y yang telah didapat maka strategi pengelolaan Hutan Rakyat Pinang Jaya terletak pada kuadran III. Kuadran III merupakan kuadran yang dibatasi oleh sumbu $\mathrm{X}$ dan sumbu $\mathrm{Y}$ yang nilai $\mathrm{X}$ maupun nilai y terdapat nilai positif dan nilai negatif (Rangkuti 2014).

Strategi yang dianjurkan adalah strategi diversifikasi (diversification strategy). Kondisi pengelolaan Hutan Rakyat Pinang Jaya berada di kuadran III yang artinya memiliki faktor-faktor kekuatan dalam kondisi yang baik seperti, tersedianya tenaga kerja keluarga, dan status penguasaan lahan. Namun petani belum dapat menghindari ancaman yang ada yaitu adanya hama dan penyakit pada tanaman. Untuk itu diperlukan strategi diversifikasi (diversification strategy) yaitu dengan memanfaatkan kekuatan yang ada. Analisis matriks SWOT digunakan untuk mendapatkan beberapa rekomendasi strategi yang tepat pada pengelolaan Hutan Rakyat Pinang Jaya. Matriks SWOT pada strategi pengelolaan Hutan Rakyat Pinang Jaya dapat dilihat pada Tabel 4 
Tabel 4. Matriks Penentuan Alternatif Strategi Pengelolaan Hutan Rakyat Pinang Jaya

\begin{tabular}{|c|c|c|}
\hline Faktor Ekternal & $\begin{array}{l}\text { Kekuatan (Strength) } \\
\text { 1. Tersedianya tenaga kerja keluarga } \\
\text { 2. Status penguasaan lahan }\end{array}$ & $\begin{array}{l}\text { Kelemahan(Weakness) } \\
\text { 1.Organisasi petani yang lemah } \\
\text { 2. Partisipasi petani yang rendah } \\
\text { terhadap kegiatan penyuluhan } \\
\text { 3. Pendapatan petani yang rendah } \\
\text { 4. Alih fungsi lahan }\end{array}$ \\
\hline $\begin{array}{l}\text { Peluang (Opportunity) } \\
\text { 1. Adanya pasar } \\
\text { 2. Adanya bantuan } \\
\text { bibit dan pupuk dari } \\
\text { pemerintah } \\
\text { 3. Adanya kebijakan } \\
\text { pemerintah yang } \\
\text { memprioritaskan } \\
\text { pemberdayaan } \\
\text { masyarakat } \\
\text { 4. Lokasi geografis yang } \\
\text { strategis } \\
\text { 5. Aksesibilitas yang } \\
\text { mudah }\end{array}$ & $\begin{array}{l}\text { Strategi } \mathrm{S}-\mathrm{O} \\
\text { 1. Memperluas jaringan pemasaran } \\
(\mathrm{S} 1)(\mathrm{O} 1)(\mathrm{O} 5) \\
\text { 2. Mengembangkan kegiatan } \\
\text { pembibitan bersama petani dengan } \\
\text { membangun lahan persemaian } \\
(\mathrm{S} 1)(\mathrm{S} 2)(\mathrm{O} 2)(\mathrm{O} 3)(\mathrm{O} 4)\end{array}$ & $\begin{array}{l}\text { Strategi W-O } \\
\text { 1. Peningkatan kapasitas } \\
\text { kelembagaan (W1)(O3) } \\
\text { 2. Menerapkan jadwal untuk } \\
\text { melaksanakan kegiatan } \\
\text { penyuluhan sesuai dengan } \\
\text { sasaran dan kondisi masyarakat } \\
\text { (W2)(O3) } \\
\text { 3. Melakukan pengajuan proposal } \\
\text { terkait dana bergulir untuk } \\
\text { usaha kehutanan (W3)(O3) } \\
\text { 4. Melakukan pemasaran hasil } \\
\text { hutan secara efektif dan } \\
\text { dilakukannya pemantauan bibit } \\
\text { secara berkala } \\
\text { (W2)(O1)(O2)(O5) } \\
\text { 5. Meningkatkan hasil produksi } \\
\text { lahan guna mencegah alih fungsi } \\
\text { lahan } \\
\text { (W4)(O3)(O4) }\end{array}$ \\
\hline $\begin{array}{l}\text { Ancaman (Threats) } \\
\text { 1. Adanya hama dan } \\
\text { penyakit pada } \\
\text { tanaman }\end{array}$ & $\begin{array}{l}\text { Strategi S-T } \\
\text { 1. Melakukan perawatan pada tanaman } \\
\text { belum menghasilkan (TBM) untuk } \\
\text { mengurangi serangan hama dan } \\
\text { penyakit } \\
(\mathrm{S} 1)(\mathrm{S} 2)(\mathrm{T} 1)\end{array}$ & $\begin{array}{l}\text { Strategi W-T } \\
\text { 1. Penguatan kelembagaan petani } \\
\text { hutan rakyat (W1)(W3)(T1) } \\
\text { 2. Mengadakan sosialisasi tentang } \\
\text { pengengendalian hama dan } \\
\text { penyakit pada tanaman } \\
\text { (W2)(T1) }\end{array}$ \\
\hline
\end{tabular}

Berdasarkan hasil analisis faktor internal dan faktor eksternal maka terdapat rekomendasi sebagaimana dalam matriks IFE dan EFE dalam analisi SWOT. Terdapat strategi SO, ST, WO dan WT pada matriks penentuan alternatif strategi. Pada strategi SO rekomendasi kegiatan yang dilakukan ialah memperluas jaringan pemasaran dan mengembangkan kegiatan pembibitan bersama petani dengan membangun lahan persemaian. Selanjutnya strategi WO rekomendasi kegiatan yang dilakukan ialah peningkatan kapasitas kelembagaan, menerapkan jadwal untuk melaksanakan kegiatan penyuluhan sesuai dengan sasaran dan kondisi masyarakat, melakukan pengajuan proposal terkait dana bergulir untuk usaha kehutanan, melakukan pemasaran hasil hutan secara efektif dan dilakukannya pemantauan bibit secara berkala, dan meningkatkan hasil produksi lahan guna mencegah alih fungsi lahan. Sementara rekomendasi dari strategi WT ialah Penguatan 
kelembagaan petani hutan rakyat dan mengadakan sosialisasi tentang pengengendalian hama dan penyakit pada tanaman. Berdasarkan matriks SWOT pada Tabel 4, maka dalam strategi pengelolaan hutan rakyat Pinang Jaya digunakan strategi ST yaitu melakukan perawatan pada tanaman belum menghasilkan (TBM) untuk mengurangi serangan hama dan penyakit. Dengan melakukan kegiatan pemeliharaan pada hutan rakyat maka hutan rakyat dapat terjamin kelestariannya. Hal ini sejalan dengan Penelitian Safe'i et al. (2015) bahwa salah satu prinsip pengelolaan hutan rakyat di Indonesia ialah pengelolaan hutan secara lestari.

Pemeliharaan tanaman muda atau TBM bertujuan untuk membuat kondisi pertumbuhan tanaman yang optimal sehingga tanaman dipersiapkan memasuki masa produktif atau tanaman menghasilkan (TM) dengan baik (Junaedi et al. 1999). Pemupukan pada TBM bertujuan untuk meningkatkan pertumbuhan vegetatif. Pemeliharaan pada tanaman ini dilakukan secara intensif dengan tujuan agar ketika hama dan penyakit menyerang akan segera dilakukan perlakuan khusus terhadap tanaman. Selain itu juga dilakukan penyuluhan mengenai pengendalian hama penyakit, irigasi, pengelolaan pasca-panen serta pemasaran hasil pertanian. Selanjutnya ialah dengan penanaman beragam jenis tanaman dalam satu lahan pertanian dengan tujuan ialah untuk menghindari ketergantungan hanya dari satu jenis tanaman pertanian saja dengan begitu, tanaman yang lain dapat berpotensi menguntungkan. Upaya peningkatan hasil produksi lahan ialah dengan cara pemberian alat dan mesin pertanian dari pemerintah. Adapun rekomendasi untuk menangani.

\section{KESIMPULAN}

Strategi pengelolaan hutan rakyat Pinang Jaya Kecamatan Kemiling Kota Bandar Lampung berada dalam posisi kuadran III, strategi yang dianjurkan adalah strategi diversifikasi. Strategi diversifikasi dengan menggunakan kekuatan untuk memanfaatkan peluang meskipun menghadapi berbagai ancaman, namun kekuatan dari faktor internal masih dimiliki, maka strategi yang harus diterapkan adalah menggunakan kekuatan untuk memanfaatkan peluang jangka panjang. Strategi pengambilan keputusan dalam hutan rakyat Pinang Jaya ialah melakukan perawatan pada TBM untuk mengurangi serangan hama dan penyakit.

\section{SARAN}

1. Diperlukan keterlibatan para pihak dan mayarakat disekitar hutan rakyat Pinang Jaya sebagai pelaku pengelolaan hutan rakyat.

2. Penguatan kelembagaan (kelompok tani hutan rakyat dan lembaga masyarakat) diantaranya melalui pemberdayaan kelembagaan.

\section{DAFTAR PUSTAKA}

Butar, V. B. , 2019, Strategi Pengembangan Hutan Rakyat di Desa Bandar Dalam Kecamatan Sidimulyo Kabupaten Lampung Selatan, Jurnal Sylva Lestari, vol 7, hal 110-117.

Junaedi, A., Wachjar, A., dan Rahman, A. , 1999, Pengaruh Penggunaan Pupuk Hayati Terhadap Pertumbuhan Belum Menghasilkan (TBM I) Kopi Robusta (Coffea 
canephora), Jurnal Bul Agron, vol 27, hal 12-17.

Rangkuti, F., 2014, Analisis SWOT Teknik Membelah Kasus Bisnis, Gramedia Pustaka Utama, Jakarta.

Safe'i, R., Hardjanto, Supriyanto., dan Sundawati, L. , 2015, Pengembangan Metode Penilaian Kesehatan Hutan Rakyat Sengon (Falcataria moluccana Miq). Barneby \& J. W. Grimes, Jurnal Penelitian Hutan Tanaman, vol 12, hal 175-187.

Safe'i, R., dan Tsani, M.K. , 2017, Penyuluhan Program Kesehatan Hutan Rakyat di Desa Tanjung Kerta Kecamatan Kedondong Kabupaten Pesawaran. Jurnal Sakai Sambayan, hal 35-36.

Safe'i, R., Erly, H., Wulandari, C. dan Kaskoyo, H. , 2018, Analisis Keanekaragaman Jenis Pohon Sebagai Salah Satu Indikator Kesehatan Hutan Konservasi. Jurnal Perenial, vol 14, hal 26-32.

Yiwen,Z. Kant, S. dan Liu, J. , 2019, Principal-Agent Relationships in Rural Governance and Benefit Sharing in Community Forestry: Evidence from a Community Forest Enterprise in China, Forest Policy and Economics Journal, vol 4, hal 1-8. 